\title{
Economic and environmental benefits of using a spray control system for the distribution of pesticides
}

\author{
F. Calegari, ${ }^{1}$ D. Tassi, ${ }^{2}$ M. Vincini ${ }^{1}$ \\ ${ }^{1}$ Centro Ricerca Analisi Spaziale e Telerilevamento, Università Cattolica del Sacro Cuore, (PC) Italy; \\ ${ }^{2}$ Azienda Sperimentale "V. Tadini", Podenzano (PC), Italy
}

\begin{abstract}
Agrochemical distribution accuracy is critical for an effective intervention with a significant impact both on production costs and on the environment. Here we present the results obtained on processingtomato crops using a sprayer boom with and without nozzle control integrated with an RTK (Real Time Kinematic) automatic guidance system. The trials were carried out on tomato crops cultivated in fields of different shapes in a farm located in the Po' Valley (Piacenza), using a self-propelled sprayer with a capacity of $1000 \mathrm{~L}$ and a $14 \mathrm{~m}$ opening boom, with a three-channel direct injection distribution system. The self-propelled sprayer was equipped with an automatic guidance system and integrated nozzle control on each boom section. Several parameters were recorded including the speed $(\mathrm{km} / \mathrm{h})$ and treated surface (ha). The analysis of the data collected shows an average overlap reduction of $15 \%$ compared to conventional guidance, a value that increases with the irregularity of the field. This technology can improve the environmental sustainability of agrochemical distribution due to the reduction in the consumption of pesticides and can improve the overall welfare of the operator as well.
\end{abstract}

\section{Introduction}

In recent years agricultural opportunities for precise management of field operations have increased considerably due to the availability of geospatial information and technology such as GPS (Global Positioning System), GIS (Geographic Information System), sensors, control systems and remote sensing. Development of new automated systems for agricultural machinery helps to improve competitiveness

Correspondence: Ferdinando Calegari, Centro Ricerca Analisi Spaziale e Telerilevamento, Università Cattolica del Sacro Cuore, (PC) Italy.

E-mail: ferdinando.calegari@unicatt.it

Key words: automatic guidance system, precision agriculture, precision spraying, processing tomato.

(c) Copyright F. Calegari et al., 2013

Licensee PAGEPress, Italy

Journal of Agricultural Engineering 2013; XLIV(s2):e32

doi:10.4081/jae.2013.s2.e32

This article is distributed under the terms of the Creative Commons Attribution Noncommercial License (by-nc 3.0) which permits any noncommercial use, distribution, and reproduction in any medium, provided the original author(s) and source are credited. and sustainability in agriculture with a positive impact on the quality of yields. RTK (Real Time Kinematic) GPS provides high-precision positioning of the machine avoiding problems for the operator due to poor vision of reference points in the field, in particular when there are no visual cues available because the crop has not yet emerged or is in the early stages of growth. The GPS system is not based on visual reliefs so its activity is not adversely affected by poor lighting or from other conditions that reduce the view of the operator (Perez-Ruiz et al., 2012; Reyns et al., 2002; Servadio and Blasi, 2003; Zhang et al., 2002). This allows high precision driving and a highly effective input distribution. The main advantage deriving from the assisted driving in a self-propelled sprayer with an RTK-GPS guidance system associated with a control system of sectors of the boom, is overlap elimination (i.e. the interruption of the distribution of a crop protection product over areas already treated in a previous path, and the interruption of the distribution over areas that do not require any treatment (edges of the field, etc.). It must be emphasized that for operations that involve the use of external inputs such as fertilizers, pesticides, etc., the application of this modern technology allows the recording of sprayer paths and product consumption and, as a consequence, provides an economic analysis of the sprayer operation (Batte and Reza Ehsani, 2006; Gualandi, 2011; Luck et al., 2010).

The main advantages of using a system with these features, both in pesticide treatment and in foliar fertilization, are the following:

- Application accuracy (i.e. distribution of the right amount of product);

- Avoiding overlapping zones or areas not treated so as to optimize the dosage per area avoiding waste, voids or overages of the products used;

- Higher speed of the operation (i.e. work area covered in a given time);

- Traceability of interventions, with recording of all the operational data (e.g. speed, location, product consumption);

In order to assess the benefits of the technique, the treatment trial was made using a self-propelled sprayer, combining the automatic guidance and nozzle-control systems on irregular shaped fields of tomato crops.

\section{Methodology}

The trial was carried out using a self-propelled sprayer with a capacity of $1000 \mathrm{~L}$ and an open boom $14 \mathrm{~m}$ wide, divided into five sections, with a distribution system with a three-channel direct injection. The sprayer adopted a GPS RTK (Real Time Kinematik) automatic guidance system with an integrated nozzle-control system of each section of the boom (i.e. with the capability of opening and closing the sections according to needs). The integrated system recorded several parameters including speed $(\mathrm{km} / \mathrm{h})$ and the area treated (ha). A speed 
record control was set up to record averaged data every $20 \mathrm{~m}$. The comparison involved the use of a sprayer with and without the boom control system. The trial was carried out on 4 fields of irregular shape, with a surface area ranging from 3.05 to 8.48 ha, in a farm located in Piacenza countryside. Processing tomato was planted in the fields in single rows with row spacing of $1.50 \mathrm{~m}$, a density of 35000 transplant seedlings/ha with a drip irrigation system. The transplant was carried out the first week of May. Throughout the season 10 treatments were performed with pesticides (herbicide, fungicide and insecticide). Data collection was performed during the treatment at the end of June. In the first phase, spreading operations were performed without the automated system (conventional way) using only water, while in the second phase carried out immediately after the first, automatic guidance and boom control systems were used and the spreading of pesticide was performed.

The use of the sprayer, with the control system of the boom activated, followed this procedure:

- A first step in order to treat a 14 meter-band along the field boundary was carried out (total width of the boom) so as to define the boundaries of the field;

- The remaining area was treated advancing in the direction of the rows and following the path pointed out by the guidance system. Once the path was intercepted, the autopilot itself drove the machinery, so that the operator was allowed to check on the boom and the operation of the nozzles.

The system is completely automatized. However, it still requires the presence of an operator and a beeping warning alarm when the machinery is approaching the end of the field. The self-propelled sprayer is also equipped with an on-board computer able to keep the amount of distributed water constant, even if speed of advancement is changed. The controller can report, in real time, any anomaly in the pump flow rate that measures the product and water, for instance, if the speed of work is increased without allowing the pumps to achieve the set dosage or in case of a slight clogging of filters that cause an abnormal water supply to the injection system. The system permits the recording of all previously set parameters (speed, level, time, etc.) which can then be downloaded, as georeferred data, into farm information systems.

\section{Results}

In the period in which comparisons were made between the two systems of treatment, the crop was at its highest vegetative growth, in good nutritional status and plant health. The weather conditions were in the normal range of temperatures and with normal humidity.

It can be noted in Figures 1 and 2 that where the treatments are performed with the control system of the boom activated, the sprayer speed in tracks near the edges of the field are higher and more homogeneous rather than where the operations are performed using the conventional approach. This is due to the increased comfort of the operator that must not continuously check obstacles on the boundaries and in previously treated areas need not manage the opening and closing of boom sections.

In Table 1 are reported the surfaces treated with the conventional system and with the automatic system. The area treated for the conventional approach is higher for all 4 fields.

The relative difference in the treated area, between the conventional and automatic approaches, should in general reduce with the increase in the size of the field and should increase with the degree of irregularity of the field.

Table 1 reports the treated surfaces and the percentage of treated

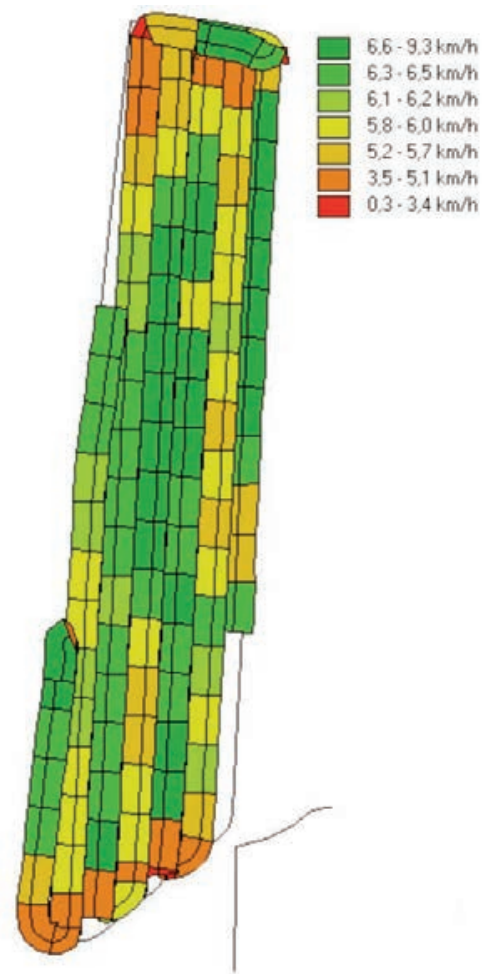

Figure 1. Shows the sprayer tracks during the treatment with the conventional system, distributing only water. The data indicates the path of the machine during the treatment in field n. 3; different colours indicate different speeds during the treatment.

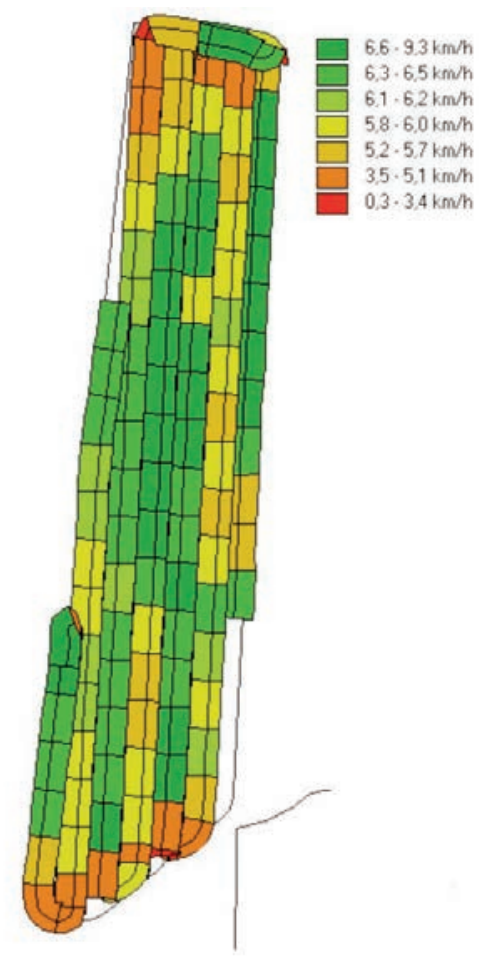

Figure 2. Shows the same parameters measured before, with automatic guidance and boom control activated. The blue colour indicates the first step of the treatment performed around the borders of field n. 3 . 
Table 1. Treated surfaces and the percentage of saving with the treatment carried out with the automatic control system of the boom compared to the conventional automatic guidance only, for each field.

\begin{tabular}{|c|c|c|c|c|}
\hline \multirow[t]{2}{*}{ Field } & \multicolumn{3}{|c|}{ Surface treated (ha) \% } & \multirow[t]{2}{*}{ Saving } \\
\hline & $\begin{array}{l}\text { Conventional } \\
\text { system }\end{array}$ & & $\begin{array}{l}\text { Boom control } \\
\text { system }\end{array}$ & \\
\hline 1 & 8.48 & & 7.58 & 10.6 \\
\hline 2 & 7.75 & & 6.65 & 14.2 \\
\hline 3 & 6.33 & & 5.18 & 18.2 \\
\hline \multirow[t]{2}{*}{4} & 3.05 & 2.53 & 17.0 & \\
\hline & & & Mean & 15.0 \\
\hline
\end{tabular}

area saved with the treatment carried out with the automatic control system of the boom compared to the conventional automatic guidance only for each field. We also have indicated the differences for each individual field, ranging from 18.2 to $10.6 \%$ with an average of $15 \%$. The difference in the treated surface is inversely proportional to the size of the field.

\section{Conclusions}

This technology drastically reduces the overlap, compared to the treatment performed in the conventional way. A significant reduction (15\%) of the quantities of agrochemicals distributed was obtained, thus improving the environmental sustainability and avoiding at the same time, areas with overages or areas not treated that could become the source of many plant diseases (fungal disease, etc.). Furthermore, in the overall assessment of this system the positive impact in terms of the well-being of the operator, arising from the reduction of working time and from a better operational comfort should be considered.

\section{References}

Batte M.T., Reza Ehsani M. 2006. The economics of precision guidance with auto-boom control for farmer-owned agricultural sprayers. Comput. Electron. Agr. 53: 28-44.

Gualandi E. 2011. Quanto si può risparmiare nelle operazioni colturali. Agricoltura, supp. 46: 30-36.

Luck J.D., Zandonadi R.S., Luck B.D., Shearer S.A. 2010. Reducing pesticide over-application with map-based automatic boom section control on agricultural sprayers. T. ASABE 53(3): 685-690.

Perez-Ruiz M., Slaughter D.C., Gliever C., Upadhyaya S.K. 2012. Tractor-based Real-time Kinematic-Global Positioning System (RTK-GPS) guidance system for geospatial mapping of row crop transplant. Biosyst. Eng. 111: $64-71$.

Reyns P., Missotten B., Ramon H., De Baerdemaeker J. 2002. A Review of Combine Sensors for Precision Farming. Precis. Agric. 3: 169 182.

Servadio P., Blasi E. 2003. I GIS e le loro applicazioni nel settore agricolo. L'Informatore Agrario n. 49, 51-56.

Zhang N., Wang M., Wang N. 2002. Precision agriculture - a worldwide overview. Comput. Electron. Agric. 36: 113-132 